\title{
Effect of zirconium oxide nanoparticles addition on the optical and tensile properties of polymethyl methacrylate denture base material
}

This article was published in the following Dove Press journal: International Journal of Nanomedicine

\author{
Mohammed M Gad' \\ Reem Abualsaud' \\ Ahmed Rahoma ${ }^{2,3}$ \\ Ahmad M Al-Thobity' \\ Khalid S Al-Abidi' \\ Sultan Akhtar ${ }^{4}$ \\ 'Department of Substitutive Dental \\ Sciences, ${ }^{2}$ Department of Restorative \\ Dental Sciences, College of Dentistry, \\ Imam Abdulrahman Bin Faisal \\ University, Dammam, Saudi Arabia; \\ ${ }^{3}$ Department of Dental Materials, \\ College of Dentistry, Al-Azhar \\ University, Assuit, Egypt; ${ }^{4}$ Department \\ of Biophysics, Institute for Research \\ and Medical Consultations, Imam \\ Abdulrahman Bin Faisal University, \\ Dammam, Saudi Arabia
}

Background: Polymethyl methacrylate (PMMA) is widely used for the fabrication of removable prostheses. Recently, zirconium oxide nanoparticles (nano- $\mathrm{ZrO}_{2}$ ) have been added to improve some properties of PMMA, but their effect on the optical properties and tensile strength are neglected.

Objective: The aim of this study was to investigate the effect of nano- $\mathrm{ZrO}_{2}$ addition on the translucency and tensile strength of the PMMA denture base material.

Materials and methods: Eighty specimens (40 dumbbell-shaped and 40 discs) were prepared out of heat-polymerized acrylic resin and divided into four groups per test $(n=10)$. The control group for each test included unreinforced acrylic, while the test groups were reinforced with $2.5,5$, and $7.5 \mathrm{wt} \%$ nano- $\mathrm{ZrO}_{2}$. Acrylic resin was mixed according to manufacturer's instructions, packed, and processed by conventional method. After polymerization, all specimens were finished, polished, and stored in distilled water at $37^{\circ} \mathrm{C}$ for $48 \pm 2$ hours. Tensile strength (MPa) was evaluated using the universal testing machine while the specimens' translucency was examined using a spectrophotometer. Statistical analysis was carried out by SPSS using the paired sample $t$-test $(p \leq 0.05)$. A scanning electron microscope was used to analyze the morphological changes and topography of the fractured surfaces.

Results: This study showed that the mean tensile strength of the PMMA in the test groups of $2.5 \% \mathrm{NZ}, 5 \% \mathrm{NZ}$, and $7.5 \% \mathrm{NZ}$ was significantly higher than the control group. The tensile strength increased significantly after nano- $\mathrm{ZrO}_{2}$ addition, and the maximum increase seen was in the $7.5 \% \mathrm{NZ}$ group. The translucency values of the experimental groups were significantly lower than those of the control group. Within the reinforced groups, the $2.5 \% \mathrm{NZ}$ group had significantly higher translucency values when compared to the $5 \% \mathrm{NZ}$ and $7.5 \% \mathrm{NZ}$ groups.

Conclusion: The addition of nano- $\mathrm{ZrO}_{2}$ increased the tensile strength of the denture base acrylic. The increase was directly proportional to the nano- $\mathrm{ZrO}_{2}$ concentration. The translucency of the PMMA was reduced as the nano- $\mathrm{ZrO}_{2}$ increased.

Clinical significance: Based on the results of the current study, the tensile strength was improved with different percentages of nano- $\mathrm{ZrO}_{2}$ additions. However, translucency was adversely affected. Therefore, it is important to determine the appropriate amount of reinforcing nano- $\mathrm{ZrO}_{2}$ that will create a balance between achieved properties - mechanical and optical.

Keywords: denture base, PMMA, tensile strength, translucency, zirconium oxide nanoparticles

\section{Introduction}

Polymethyl methacrylate (PMMA) is one of the most commonly used dental materials in prosthodontics due to its desirable characteristics, such as excellent aesthetic properties, ease of handling and repair, accurate reproduction of surface details, lack of toxicity, and cost-effectiveness. ${ }^{1,2}$ However, it has some relative inadequacies and 
poor mechanical properties that can cause the denture base to fracture or affect the longevity of the dentures..$^{2-4}$ After years of use, dentures will deteriorate and the bases may fracture due to constant exposure to external stresses caused by poor occlusion or fit. ${ }^{4,5}$ Several attempts have been made to improve the physical properties of the denture base material, such as the chemical modification of PMMA, development of an alternative material to PMMA, reinforcement with other materials, such as fibers, and use of macro- and nanofillers. ${ }^{6,7}$ It was found that the physical properties of acrylic resins are influenced by the addition of nanoparticles as the reinforcing agent. ${ }^{8,9}$ Previous studies and the international standards for denture bases found that PMMA-containing nanoparticles outperform conventional PMMA. ${ }^{10,11}$ Recently, studies have investigated the effect of incorporating inorganic nanoparticles into PMMA to improve its properties. ${ }^{7,12-14}$ The shape and size as well as the concentration and interaction of these nanoparticles with a polymer matrix determine the properties of a polymer nanocomposite mixture. ${ }^{13}$ Many reports proved the dependence of acrylic resin properties on nanoparticle concentrations. ${ }^{8,9,15,16}$ Nanomaterials are known for their superior characteristics compared to the conventional ones. ${ }^{13,14}$ When these nanomaterials are incorporated into a polymer matrix as fillers, propitious features of both constituents integrate to improve the optical and mechanical properties of nanocomposites. ${ }^{14}$

Among these, zirconium oxide nanoparticles (nano- $\mathrm{ZrO}_{2}$ ) are usually used mechanically to reinforce polymers and improve the strength of the reinforced PMMA matrix. ${ }^{10,17-19}$ Good adhesion and homogeneous dispersion of nanoparticles within a resin matrix improved the flexural properties of a polymer/nanoparticles composite. ${ }^{20}$ Thus, silane coupling agents used to treat the surface of nano- $\mathrm{ZrO}_{2}$ could eliminate its aggregation and improve its compatibility with the polymer matrix. ${ }^{20,21}$

In general, dentures are subjected to a combination of tensile, compressive, and shear forces as well as their susceptibility to sudden drop, which may result in denture base fracture. ${ }^{22}$ Aiming to improve these properties, some inorganic fillers were used to reinforce the PMMA denture base. ${ }^{23}$ Metal oxide nanoparticles have recently been investigated. In 2007, Singh et al coated alumina nanoparticles with 3-(trimethoxysilyl) propyl methacrylate (TMSPM) to form a PMMA/alumina nanocomposite, which positively enhanced the impact and tensile properties of the denture base over pure PMMA. ${ }^{24}$

Recently, nano- $\mathrm{ZrO}_{2}$ received great attention because of its excellent biocompatibility as well as its white color, which make it less likely to alter the aesthetics in comparison to other metal oxide nanoparticles. ${ }^{20,23}$ The selection of nano- $\mathrm{ZrO}_{2}$ as a filler in this study was based on the properties of this filler, which can improve the mechanical properties of acrylic resins. $\mathrm{ZrO}_{2}$ possesses a variety of beneficial properties, such as excellent toughness and mechanical strength, abrasion and corrosion resistance, and biocompatibility. ${ }^{18,23-25}$ Nano- $\mathrm{ZrO}_{2}$ has high mechanical properties, allowing it to withstand crack propagation, and it is known for having the highest hardness among any oxide. It exhibits a crystalline structure, which causes a higher value of opacity. ${ }^{26,27}$ There are many factors that affect the mechanical and physical properties of the $\mathrm{PMMA} / \mathrm{ZrO}_{2}$ nanocomposite, such as filler type, shape, size, proportion, distribution, and composition of the matrix. ${ }^{20,23}$

Good optical properties of PMMA reinforced with inorganic fillers are vital. PMMA permits filler reinforcements, which may influence the translucency properties and, consequently, the aesthetic values. Trials, through the incorporation of filler particles (zirconia, silica, alumina, glass fiber, tin, and copper), to improve the properties of PMMA were all explored. ${ }^{28}$ Aszrin et al evaluated the translucency of PMMA provisional crowns reinforced with different concentrations of zirconia-alumina-silica fillers and concluded that the different concentrations exhibited an erratic influence on the PMMA translucency. ${ }^{29}$

For the fabrication of removable prosthesis, polymers with superior properties and final aesthetics are favored. Therefore, the optical properties of each material have to be considered by dental practitioners. Translucency is defined as the ability of a material to permit some light to passing through its structure, thus allowing the background underneath to show through. ${ }^{30,31}$ It is a designation of a partial transparency or a middle point between complete opacity and complete transparency. ${ }^{32}$ The translucency property for any material results from the color difference between the thickness of the examined material over a white background and the same uniform thickness of that material over a black background. This color difference provides a specific value in relation to the common visual perception of translucency. ${ }^{33}$

Although several studies have been performed to evaluate the effect of nano- $\mathrm{ZrO}_{2}$ addition on different properties of PMMA denture base material, translucency and tensile strength properties were neglected. Therefore, this study intended to evaluate the effects of nano- $\mathrm{ZrO}_{2}$ addition on the translucency and tensile properties of PMMA. Additionally, the study sought to perform a fracture surfaces analysis of the fractured surfaces using scanning electron microscopy (SEM). The hypothesis of this study was that addition of nano- $\mathrm{ZrO}_{2}$ will improve the tensile strength of 
the PMMA denture base materials but will adversely affect the translucency.

\section{Materials and methods Preparation of specimens}

Eighty specimens were divided into eight groups to test tensile strength and translucency with 10 specimens for each group. Per each test, there were four groups $(n=10)$, according to nano- $\mathrm{ZrO}_{2}$ concentrations. The dimensions of the specimens for the tensile strength test were selected according to ISO standard \#1567, and the tensile strength of the specimens was compared with the controls. ${ }^{34}$ Dumbbell-shaped metal plates with dimensions of $32.5 \times 6 \times 2.5 \pm 0.03 \mathrm{~mm}$ for tensile strength test were invested in dental stone (Fujirock EP; GC, Leuven, Belgium) within the lower half of the flask (61B Two Flask Compress; Handler Manufacturing, Westfield, NJ, USA). A separating media was applied on the stone surface before seating the upper half of the flask and filling it with another layer of stone. After the setting of stone, the flasks containing the dumbbell-shaped metal plates were opened, and the metal plates were removed, thus creating empty molds for the denture base material.

For the translucency test, pink base plate wax (Cavex Set up Wax; Cavex, Haarlem, the Netherlands) was cut into $15 \times 2 \pm 0.01 \mathrm{~mm}$. The discs were then flasked in a similar manner. After the setting of stone, the flasks were dewaxed in boiling water for $5 \mathrm{~min}$, opened, washed with clean running water, coated with a tin-foil substitute (Isol Major; Major Prodotti Dentari Spa), and allowed to cool down before packing.

\section{Size of nano- $\mathrm{ZrO}_{2}$ particles}

Transmission electron microscopy (TEM) (FEI, Morgagni, Czech Republic) was used to measure the size of the nano$\mathrm{ZrO}_{2}$ (1314-23-4; Sigma-Aldrich, Co., St Louis, MO, USA). The nano- $\mathrm{ZrO}_{2}$ powder was dispersed in ethanol, sonicated for $5 \mathrm{~min}$, and deposited onto the TEM grid, having a carbon support film. The grid was dried prior to mounting for TEM. A TEM at $80 \mathrm{kV}$ was used to record the images. Gatan digital micrograph software was used to measure the size and calculate the average size of the particles. The nano$\mathrm{ZrO}_{2}$ powder used had an average grain size of $40 \pm 2 \mathrm{~nm}$ (Figure 1), a surface area of $9 \pm 2 \mathrm{~m}^{2} / \mathrm{g}$, and a purity of $99.9 \%$.

\section{Silanization of nano- $\mathrm{ZrO}_{2}$ particles}

The TMSPM silane coupling agent (Shanghai Richem International Co., Ltd., Shanghai, China) was added to the nano$\mathrm{ZrO}_{2}$ particles to coat the surface and form reactive groups, thus allowing for interaction between the resin matrix and

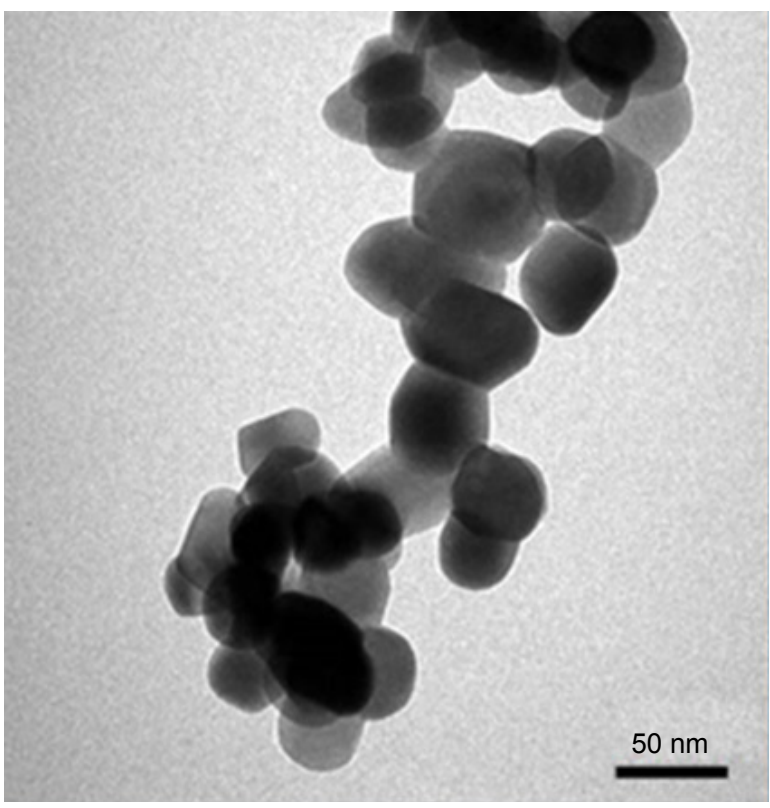

Figure I Representative TEM images of nano- $\mathrm{ZrO}_{2}$.

Note: The average particle size was estimated to be $\sim 40 \mathrm{~nm}$.

Abbreviations: nano- $\mathrm{ZrO}_{2}$, zirconium oxide nanoparticles; TEM, transmission electron microscopy.

nanoparticles and eventual bonding. ${ }^{20}$ The process of coating involved dissolving $0.3 \mathrm{~g}$ of TMSPM in $100 \mathrm{~mL}$ of acetone followed by adding $30 \mathrm{~g}$ of nano- $\mathrm{ZrO}_{2}$ to the TMSPM/acetone mix and stirring for 60 min with a magnetic stirrer (Cimarec Digital Stirring Hotplates, SP131320-33Q; Thermo Fisher Scientific, Waltham, MA, USA). The mixture was placed under vacuum at $60^{\circ} \mathrm{C}$ in a rotary evaporator at $150 \mathrm{rpm}$ for $30 \mathrm{~min}$ to eliminate the acetone. The sample was then heated at $120^{\circ} \mathrm{C}$ for $2 \mathrm{~h}$ to increase the interaction between nano$\mathrm{ZrO}_{2}$ and TMSPM and subsequently coupling reaction to occur, ${ }^{35,36}$ and then cooled to obtain silanized nano- $\mathrm{ZrO}_{2} \cdot{ }^{20,23}$ TMSPM can couple the nano- $\mathrm{ZrO}_{2}$ PMMA. Figure 2 shows the schematic representation of the chemical reaction of silanization process, the bonding formed between the nano$\mathrm{ZrO}_{2}$ and TMSPM that mainly depends on the functional groups of TMSPM. ${ }^{37,38}$ After hydrolysis of TMSPM, silanol is formed, and alkoxy group is replaced by hydroxyl group $(\mathrm{Si}-\mathrm{OH})$ that reacts with hydroxyl group of zirconia $(\mathrm{Zr}-\mathrm{OH})$ followed by dehydration condensation reaction resulting in the formation of chemical bonds between nano- $\mathrm{ZrO}_{2}$ and TMSPM ( $\mathrm{Zr}-\mathrm{O}-\mathrm{Si})$. On the other hand, organofunctional groups $(\mathrm{X})$ contain double bond $(\mathrm{C}=\mathrm{C})$ that can bond to PMMA. ${ }^{44,45}$

\section{Preparation of $\mathrm{PMMA} / \mathrm{ZrO}_{2}$ nanocomposite} The already silanized nano- $\mathrm{ZrO}_{2}$ particles were weighed using a digital balance (S-234; Denver Instrument, Gottingen, Germany) and then mixed with heat-polymerized acrylic 

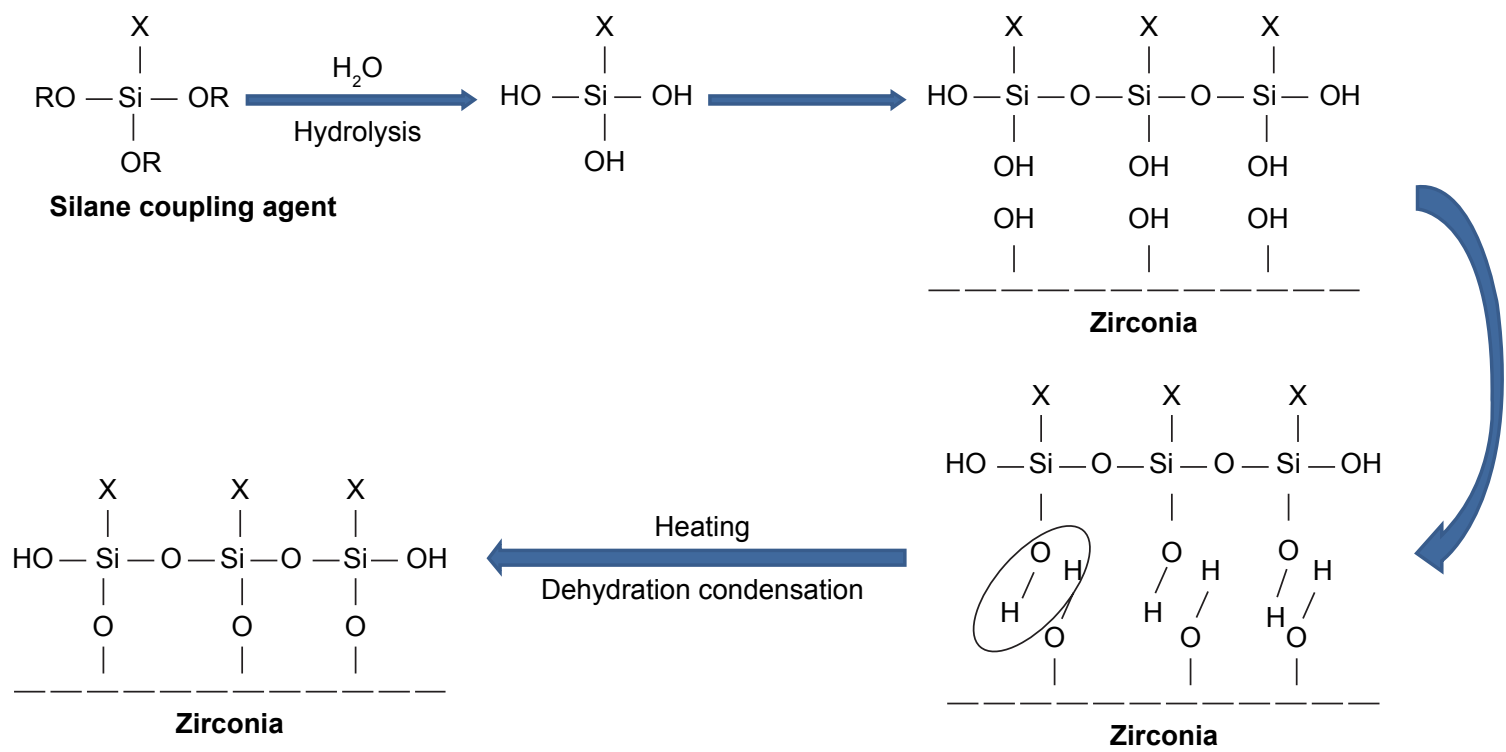

Figure 2 Schematic diagram of silanization of nano- $\mathrm{ZrO}_{2}$. Abbreviation: nano- $\mathrm{ZrO}_{2}$, zirconium oxide nanoparticles.

polymer powder (Major base 20; Major Prodotti Dentari, SPA, Moncalieri, Italy) at concentrations of 2.5, 5, and 7.5 $\mathrm{wt} \%$. The mixture of acrylic powder and silanized nano- $\mathrm{ZrO}_{2}$ was meticulously stirred for $30 \mathrm{~min}$ to ensure the homogeneity of the mix and uniformity of color. ${ }^{23,35}$

\section{Specimens processing}

Based on the manufacturer's instructions, the heat-polymerized acrylic resin (3 polymer: 1 monomer volume) was mixed and left to reach a dough stage at room temperature. Acrylic dough was packed into the mold spaces, the flask halves were closed and pressed using a hydraulic press for $5 \mathrm{~min}$, and then allowed to rest for $30 \mathrm{~min}$ before polymerization. The flask was placed into a water bath curing unit ( $\mathrm{KaVo}$ Elektrotechnisches Werk GmbH, Leutkirch, Germany) and processed by heating it to $74^{\circ} \mathrm{C}$ for $90 \mathrm{~min}$ and then to $100^{\circ} \mathrm{C}$ for $30 \mathrm{~min}$. The flask was slowly cooled to room temperature for $30 \mathrm{~min}$ followed by an immersion in cool tap water for 15 min before deflasking. After complete polymerization and cooling, the flask was opened and the acrylic specimens were taken out of the flask and finished using acrylic bur, where any excess resin was removed. Finishing of the specimens was done using silicon carbide discs (Grit 600) by a polishing machine (MetaServ 250 Grinder-Polisher, Buehler, Lake Bluff, IL, USA) at $250 \mathrm{rpm}$, followed by a cloth wheel, and a $0.5-\mu \mathrm{m}$ diamond suspension to polish. All the specimens were examined to confirm proper dimensions using a digital caliber with a $0.01 \mathrm{~mm}$ accuracy (Neiko 01407A Electronic Digital Caliper). The specimens were divided into four test groups for each test, according to the nano- $\mathrm{ZrO}_{2}$ concentration (Table 1 and Figure 3).

\section{Tensile strength test}

The dumbbell-shaped specimens were conditioned at $37^{\circ} \mathrm{C}$ for $48 \pm 2 \mathrm{~h}$ prior to testing. The specimens were individually fixed in a vice that grips onto a universal testing machine (Instron 8871; Instron Co., Norwood, MA, USA) with a load cell of $5 \mathrm{kN}$ and a chart speed of $20 \mathrm{~mm} / \mathrm{min}$. Each individual specimen was tension loaded until fracture at a crosshead speed of $0.5 \mathrm{~mm} / \mathrm{min}$. The failure load was recorded in newtons $(\mathrm{N})$. The value of the tensile strength was calculated using the following formula: (TS = F/A), where, TS is the tensile strength $\left(\mathrm{N} / \mathrm{mm}^{2}\right), \mathrm{F}$ is the load at failure $(\mathrm{N})$, and $\mathrm{A}$ is the area of a cross-section at failure $\left(\mathrm{mm}^{2}\right)$.

\section{SEM}

SEM (INSPECT S50; FEI, Hillsboro, OR, USA) was used to examine the surface and fractured cross-section of the specimens. The acceleration voltage, used to perform SEM

Table I Specimens grouping and specifications

\begin{tabular}{lll}
\hline Groups & Specifications & Number \\
\hline Control & $\begin{array}{l}\text { Unreinforced heat-polymerized acrylic resin } \\
2.5 \% \mathrm{NZ}\end{array}$ & $\begin{array}{l}2.5 \text { wt\% nano- } \mathrm{ZrO} \\
2\end{array}$ reinforced heat-polymerized \\
acrylic resin & 20 \\
$5 \% \mathrm{NZ}$ & $\begin{array}{l}5 \text { wt\% nano-ZrO } \\
\text { acrylic resin }\end{array}$ & 20 \\
$7.5 \% \mathrm{NZ}$ & $\begin{array}{l}7.5 \text { wt\% nano- } \mathrm{ZrO}_{2} \text { reinforced heat-polymerized } \\
\text { acrylic resin }\end{array}$ & 20 \\
\hline
\end{tabular}




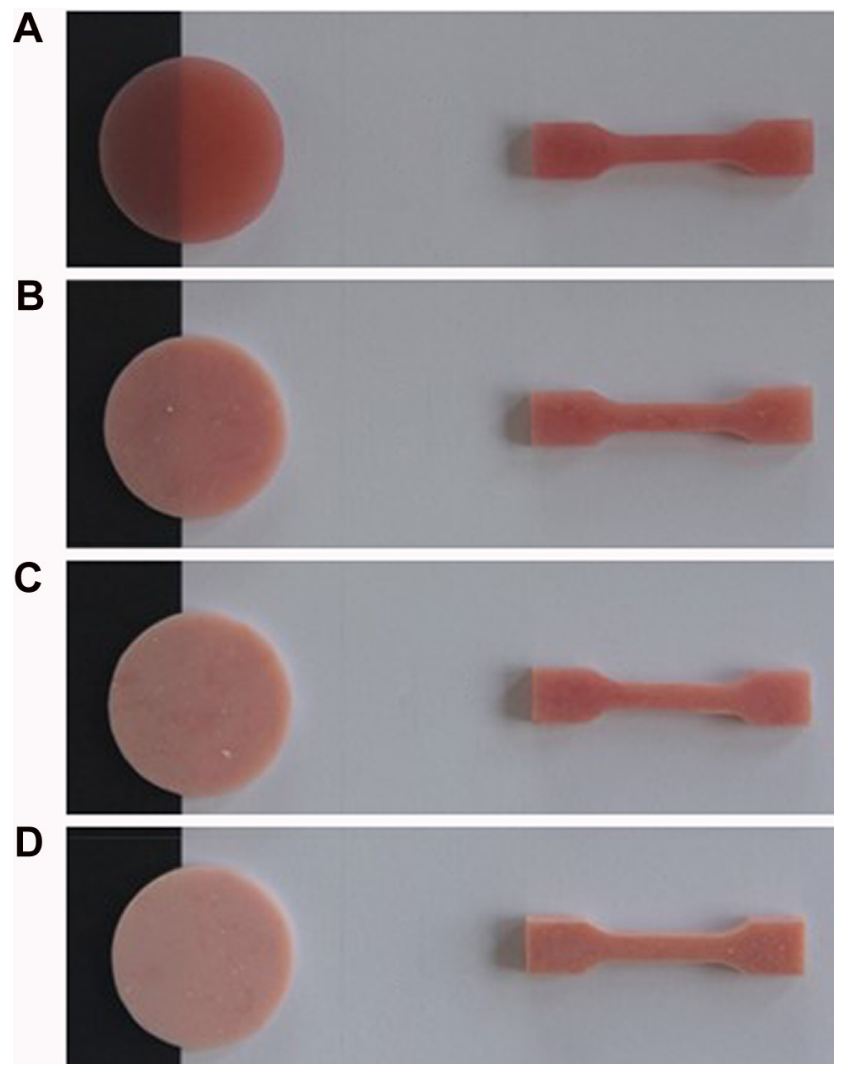

Figure 3 Specimens prepared for testing: disc shape obtained for translucency test and dumbbell shape for tensile strength test.

Note: (A) Unreinforced specimen ( $n=20)$, acrylic resin specimens reinforced with (B) $2.5 \%$ nano- $\mathrm{ZrO}_{2}(\mathrm{n}=20)$, (C) $5 \%$ nano- $\mathrm{ZrO}_{2}(\mathrm{n}=20)$, and (D) $7.5 \%$ nano- $\mathrm{ZrO}_{2}$ $(n=20)$.

Abbreviations: $2.5 \% \mathrm{NZ}, 2.5 \mathrm{wt} \%$ nano- $\mathrm{ZrO}_{2}$ reinforced heat-polymerized acrylic resin; $5 \% \mathrm{NZ}, 5$ wt\% nano- $\mathrm{ZrO}_{2}$ reinforced heat-polymerized acrylic resin; $7.5 \% \mathrm{NZ}$, $7.5 \mathrm{wt} \%$ nano- $\mathrm{ZrO}_{2}$ reinforced heat-polymerized acrylic resin; nano- $\mathrm{ZrO}_{2}$, zirconium oxide nanoparticles.

evaluation, was set at $20 \mathrm{kV}$ and the working distance was $\sim 10 \mathrm{~mm}$ with a 3.5 spot size. A gold coating was applied using a sputter coating machine (Quorum, Q150R ES, UK) to overcome the non-conductive nature of the material. The specimens were mounted on a metallic stub using a doublesided adhesive tape. To obtain a better visual inspection, images were taken at different magnifications to note important features about the nature of the failure.

\section{Translucency test}

Reflectance values were measured using a spectrophotometer (Color-Eye $\left.{ }^{\circledR} 7000 \mathrm{~A}, \mathrm{X}-\mathrm{Rite}\right)$. The small size $(10 \times 7.5 \mathrm{~mm})$ of the aperture viewing area was selected. The spectrophotometer was calibrated using the provided white tile and black trap, following the manufacturer's recommendations. Each specimen was stabilized against the port, supported at the back by a white or black reference material, and then the support arm was closed. Color measurements of the coordinates $\left(\mathrm{L}^{*}, \mathrm{a}^{*}, \mathrm{~b}^{*}\right)$ of the Commission Internationale
Table 2 Mean, SD, and $p$-values of the specimens tested for tensile strength

\begin{tabular}{lllll}
\hline Sample & Control (C) & $\mathbf{2 . 5 \% N Z ~ ( X ) ~}$ & 5\%NZ (Y) & $\mathbf{7 . 5 \% N Z ~ ( Z ) ~}$ \\
\hline Max & 62.67 & 67.90 & 70.02 & 71.76 \\
Min & 53.85 & 59.55 & 63.64 & 64.43 \\
Mean \pm SD & $51.77 \pm 3.14^{\mathrm{a}}$ & $63.55 \pm 2.91^{\mathrm{b}}$ & $66.32 \pm 1.87^{\mathrm{c}}$ & $69.59 \pm 1.00^{\mathrm{d}}$ \\
$95 \% \mathrm{Cl}$ & $55.7-60.2$ & $61.5-65.6$ & $65.0-67.7$ & $67.5-70.9$ \\
p-value & - & vs C $=0.00 \mathrm{I}$ & vs $\mathrm{C}=0.000$ & vs $\mathrm{C}=0.012$ \\
& - & - & vs $X=0.003$ & vs $\mathrm{X}=0.000$ \\
& - & - & - & vs $\mathrm{Y}=0.000$ \\
\hline
\end{tabular}

Notes: One-way ANOVA and a paired sample $t$-test $(p<0.05)$ indicate differences among nano- $\mathrm{ZrO}_{2}$ concentrations as shown by differences in superscripts letters horizontally.

Abbreviations: C, unreinforced heat-polymerized acrylic resin; $2.5 \% \mathrm{NZ}, 2.5 \mathrm{wt} \%$ nano- $\mathrm{ZrO}_{2}$ reinforced heat-polymerized acrylic resin; $5 \% \mathrm{NZ}, 5 \mathrm{wt} \%$ nano- $\mathrm{ZrO}_{2}$ reinforced heat-polymerized acrylic resin; 7.5\% NZ, $7.5 \mathrm{wt} \%$ nano- $\mathrm{ZrO}_{2}$ reinforced heat-polymerized acrylic resin.

de l'Eclairage (CIE) system were made for every disc against each background. Three readings were made for each specimen, and the average was automatically presented by the software. The data were tabulated and translucency was calculated using the following equation: $\mathrm{TR}=\left[\left(\mathrm{L}^{*}{ }_{\text {white }}-\mathrm{L}^{*}{ }_{\text {black }}\right)^{2}+\left(\mathrm{a}^{*}{ }_{\text {white }}{ }^{-}\right.\right.$ $\left.\left.\mathrm{a}^{*}{ }_{\text {black }}\right)^{2}+\left(\mathrm{b}^{*}{ }_{\text {white }}-\mathrm{b}^{*}{ }_{\text {black }}\right)^{2}\right]^{1 / 2}$, where TR is the translucency. ${ }^{39}$

\section{Statistical analysis}

SPSS-20.0 (IBM, Chicago, IL, USA) was used for statistical data analysis. The results of the tensile strength and translucency were presented as mean, SD, minimum, and maximum observations (Tables 2 and 3). A paired sample $t$-test was applied to compare the means pairwise between the control and interventional groups (ie, $2.5 \% \mathrm{NZ}$, $5 \% \mathrm{NZ}$, and $7.5 \% \mathrm{NZ}$ ). A $95 \%$ confidence interval of the differences of means was also calculated. If the $p$-value was $\leq 0.05$, then the difference was considered statistically significant.

Table 3 Mean, SD, and $p$-values of translucency

\begin{tabular}{lllll}
\hline Sample & Control (C) & $\mathbf{2 . 5 \% N Z ~ ( X ) ~}$ & $\mathbf{5 \% N Z}(\mathbf{Y})$ & $\mathbf{7 . 5 \% N Z ~ ( Z ) ~}$ \\
\hline Max & 13.89 & 4.02 & 2.38 & 2.53 \\
Min & 12.02 & 3.20 & 1.85 & 1.62 \\
Mean \pm SD & $12.93 \pm 0.653^{\mathrm{a}}$ & $3.505 \pm 0.245^{\mathrm{b}}$ & $2.097 \pm 0.147^{\mathrm{c}}$ & $2.023 \pm 0.32 \mathrm{I}^{\mathrm{c}}$ \\
$95 \% \mathrm{Cl}$ & $12.46-13.40$ & $3.33-3.68$ & $\mathrm{I} .99-2.20$ & $1.79-2.25$ \\
$p$-value & - & $\mathrm{v} / \mathrm{s} \mathrm{C}=0.000$ & $\mathrm{v} / \mathrm{s} \mathrm{C}=0.000$ & $\mathrm{v} / \mathrm{s} \mathrm{C}=0.000$ \\
& - & - & $\mathrm{v} / \mathrm{s} X=0.000$ & $\mathrm{v} / \mathrm{s} \mathrm{X}=0.000$ \\
& - & - & - & $\mathrm{v} / \mathrm{s} \mathrm{Y}=0.564$ \\
\hline
\end{tabular}

Notes: One-way ANOVA and a paired sample $t$-test $(p<0.05)$ indicate differences among nano- $\mathrm{ZrO}_{2}$ concentrations as shown by differences in superscripts letter horizontally; same letters indicate no significant difference.

Abbreviations: C, unreinforced heat-polymerized acrylic resin; $2.5 \% \mathrm{NZ}, 2.5 \mathrm{wt} \%$ nano- $\mathrm{ZrO}_{2}$ reinforced heat-polymerized acrylic resin; $5 \% \mathrm{NZ}, 5 \mathrm{wt} \%$ nano- $\mathrm{ZrO}{ }_{2}$ reinforced heat-polymerized acrylic resin; 7.5\% NZ, $7.5 \mathrm{wt} \%$ nano- $\mathrm{ZrO}_{2}$ reinforced heat-polymerized acrylic resin. 


\section{Results}

The mean, $\mathrm{SD}$, and $p$-values of the specimens tested for tensile strength are summarized in (Table 2). Regarding the data of the tensile strength, the experimental groups reinforced with the nano- $\mathrm{ZrO}_{2}$ fillers showed a significant increase in the tensile strength when compared with the control group $(58.07 \pm 3.14 \mathrm{MPa})$. Furthermore, there were significant changes in the tensile strengths for the nano- $\mathrm{ZrO}_{2}$ reinforced groups $2.5 \% \mathrm{NZ}, 5 \% \mathrm{NZ}$, and $7.5 \% \mathrm{NZ}$ by $63.55 \mathrm{MPa}, 66.32$ $\mathrm{MPa}$, and 69.59 $\mathrm{MPa}$, respectively (Table 2).

Figure 1 shows the TEM image of the nano- $\mathrm{ZrO}_{2}$; several such images were taken to measure the average size of the particles. In general, the particles showed round morphology. The average size of the particle was estimated to be around $40 \pm 2 \mathrm{~nm}$. Figure 4 shows the SEM micrographs of the fractured specimens at 2,000× magnifications and at different concentrations of the nano- $\mathrm{ZrO}_{2}$. The control specimen (Figure 4A) shows flake- or sheet-like structures of certain thickness and broad scattered pores with a dimension of $50 \mu \mathrm{m}$. Conversely, the treated samples show a compact morphology with diminutive pores a few microns in diameter (Figure 4B), which were preoccupied by zirconia nanoparticles. The pores disappeared as we moved from Figure 4B $(2.5 \% \mathrm{NZ})$ to Figure $4 \mathrm{D}(7.5 \% \mathrm{NZ})$. Furthermore, the SEM revealed a good dispersion of nano- $\mathrm{ZrO}_{2}$ in the PMMA matrix, with the $2.5 \% \mathrm{NZ}$ group showing the most regular fracture surface. As the nano- $\mathrm{ZrO}_{2}$ concentrations were increased to $7.5 \% \mathrm{NZ}$, an obvious ductile dimple pattern, demonstrating a typical ductile fracture, was seen.

The mean and SD of the translucency test are presented in Table 3. There was a significant reduction in the specimens' translucency of the experimental groups when compared to the
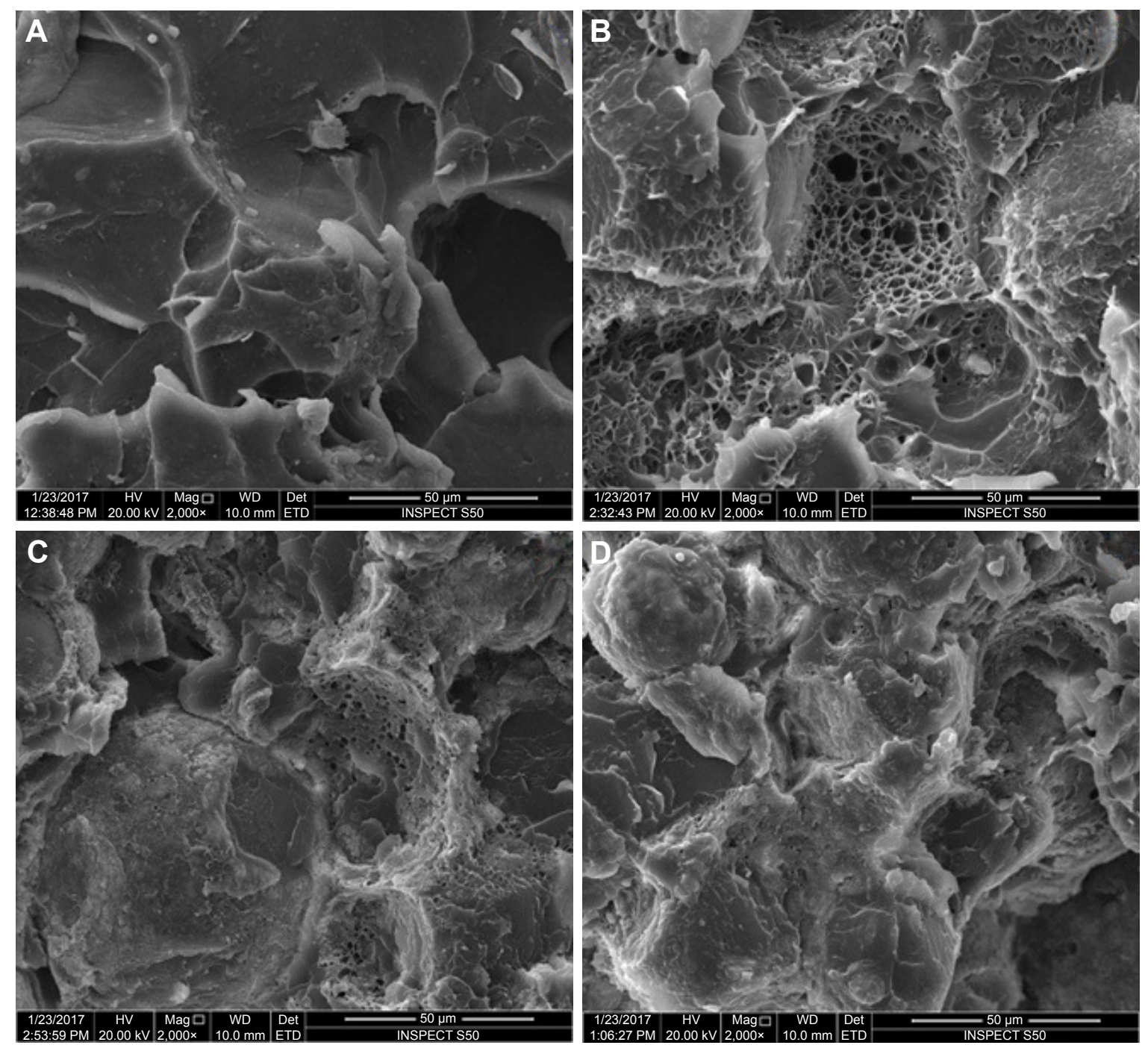

Figure 4 Representative SEM images.

Note: $(\mathbf{A})$ Unreinforced specimens, acrylic resin specimens reinforced with (B) $2.5 \% \mathrm{NZ},(\mathbf{C}) 5 \% \mathrm{NZ}$, and (D) $7.5 \% \mathrm{NZ}$.

Abbreviations: SEM, scanning electron microscopy; $2.5 \% \mathrm{NZ}, 2.5 \mathrm{wt} \%$ nano- $\mathrm{ZrO}_{2}$ reinforced heat-polymerized acrylic resin; $5 \% \mathrm{NZ}, 5 \mathrm{wt} \%$ nano-ZrO ${ }_{2}$ reinforced heatpolymerized acrylic resin; 7.5\% NZ, $7.5 \mathrm{wt} \%$ nano- $\mathrm{ZrO}_{2}$ reinforced heat-polymerized acrylic resin. 
control group (12.93 \pm 0.653$)$. Within the reinforced groups, the $2.5 \% \mathrm{NZ}$ group enabled the nanocomposite to possess the highest translucency value $(3.505 \pm 0.245)$ followed by the $5 \% \mathrm{NZ}$ group $(2.097 \pm 0.147)$, while the $7.5 \% \mathrm{NZ}$ group showed the lowest translucency value $(2.023 \pm 0.321)$.

\section{Discussion}

The current study aimed to investigate the effect of the addition of nano- $\mathrm{ZrO}_{2}$ on the translucency and tensile properties of the PMMA denture base material. The results found that all experimental groups showed increased tensile strength in direct proportion to the concentrations of nano- $\mathrm{ZrO}_{2}$, but the translucency decreased; therefore, the hypothesis of this study was accepted.

According to the results of the current study, a significant increase in the tensile strength was found with the addition of $2.5 \%, 5 \%$, and $7.5 \%$ of nano- $\mathrm{ZrO}_{2}$. This outcome is in agreement with previous studies, which found that the addition of nano- $\mathrm{ZrO}_{2}$ significantly increases the mechanical properties in a direct relation. ${ }^{20,40}$ The amount of filler used to reinforce the acrylic resin is another important factor affecting the mechanical properties. ${ }^{40}$ The percentage of filler used for reinforcement should be in such amounts that it will disperse evenly into the resin matrix without interrupting its continuity. ${ }^{5}$

The increase in tensile strength may be attributed to the good dispersion of the nano- $\mathrm{ZrO}_{2}$ fillers that improve the strength due to their nanosize, which helps in filling the matrix interstitially. Moreover, the strong adhesion formed between the coupling agent on the surface of the nano- $\mathrm{ZrO}_{2}$ and PMMA matrix improves the mechanical properties of the nanocomposites. ${ }^{10,23}$ Furthermore, the large interfacial area of nanoparticles provides more contact points between the PMMA and nano- $\mathrm{ZrO}_{2}$, thereby improving mechanical interlocking and allowing a change in the properties of the $\mathrm{ZrO}_{2} / \mathrm{PMMA}$ nanocomposite provided by plastic deformation and an increase in the PMMA matrix ductility. ${ }^{41-43}$ Moreover, the existing, well-distributed nano- $\mathrm{ZrO}_{2}$ transfer stresses from the weak PMMA matrix to the strong nano- $\mathrm{ZrO}_{2}$ filler.

Contrary to the results found in this study, Chladek et al showed that the mechanical properties of nanocomposites reinforced by silver nanoparticles decreased as the silver nanoparticle concentrations increased. ${ }^{46}$ Similarly, Chatterjee in 2010 showed that increasing the titanium oxide nanoparticle content decreased the tensile strength. ${ }^{15}$ Chladek et al and Chatterjee attributed the decrease in tensile strength to the agglomeration of the incorporated nanoparticles, acting as stress concentration centers in the matrix and unfavorably decreasing the mechanical properties of the resin. ${ }^{15,46,47}$
Also, the presence of agglomerated fillers forming loosely attached clusters, which affect the mode of crack propagation, reduces the tensile strength. ${ }^{20,15}$ However, the results of this study showed an increase in tensile strength, even with higher concentrations. These differences may be due to the nature of the nanoparticles used in addition to salinization effect of the nano- $\mathrm{ZrO}_{2}$.

The SEM micrographs showed good surface characteristic with different nano- $\mathrm{ZrO}_{2}$ concentrations. Moreover, no big agglomeration of these nanoparticles was observed, indicating a uniform particle distribution. The SEM analysis showed that as the concentration increases, the polymer matrix is filled with nanoparticles that will stop crack propagation, resulting in stronger material. In addition, good dispersion of the nanoparticles into the resin matrix filled the inter-polymeric chain spaces, which shows the importance of the additive content of the nanoparticles. ${ }^{10,15}$

The heat-cured acrylic resin comes in a translucent pink color, which is then mixed with a monomer and undergoes heat polymerization. In general, the PMMA is translucent, has good biocompatibility, and has a low toxicity. ${ }^{15,28,29}$ Despite its ease of manipulation and low cost, it is prone to several disadvantages, such as poor mechanical and surface properties, resulting in denture fracture, porosities, plaque accumulations, and stains. ${ }^{1,6,15}$ To overcome these weak properties, PMMAs are reinforced with nano- $\mathrm{ZrO}_{2}$ to improve the mechanical properties without adversely affecting the aesthetics. ${ }^{5,26}$

Overall, the diffuse reflectance spectra readings display the amount of ultraviolet (UV) beam reflected by the UV-VIS spectrophotometer. The higher readings exhibit a higher reflectance of UV beam, which shows an increase in the average total of translucence, whereas lower readings exhibit a lower reflectance, which shows a decrease in the average total of translucence. ${ }^{29}$ When the measured translucency approaches zero, the material is considered to be completely opaque. As the value increases, translucency also increases. ${ }^{32}$ Kelly et al recognized translucency as being a prime factor in determining the aesthetics and, therefore, a key property in material selection. ${ }^{48}$ The success of a removable prosthesis is dependent on the appearance of the denture base to that of the patient's oral mucosa, which mainly depends on the translucency. ${ }^{30}$ To render the prosthesis with a natural look, a desired level of translucency is mandatory. The idea behind this is to create harmonious optical properties between the removable prosthesis and underlying mucosa given that a "chameleon" effect, which allows the underlying soft tissues to show through the PMMA denture base. ${ }^{49,50}$ 
It was found that the addition of nano- $\mathrm{ZrO}_{2}$ decreased the translucency of the investigated material in direct relation to its concentrations. In agreement with the results of the current study, Aszrin et al in 2016 concluded that the combination of different concentrations of zirconium oxide, aluminum oxide, and silicon oxide fillers exhibits an unpredictable negative influence on translucency. ${ }^{29}$ This decrease in translucency may be attributed to differences in the optical properties of the nano- $\mathrm{ZrO}_{2}$ and its distributions within the resin matrix. Due to the crystallinity nature of nano- $\mathrm{ZrO}_{2}$ (high opacity), the absorbed light was not allowed to pass through, thereby decreasing translucency. This change is inversely proportional to the concentration of nano- $\mathrm{ZrO}_{2}{ }^{26}$ Meanwhile, the white color of zirconia powder does not compromise the aesthetic appearance, unlike its metal filler counterparts, such as aluminum, copper, or silver. ${ }^{5}$ The nano- $\mathrm{ZrO}_{2}$ cluster formations also prevented light transmission, thereby decreasing translucency. This finding is in agreement with Shirkavand and Moslehifard's study, in which they stated that it is essential to prevent the agglomeration of particles used within the matrix in order to prevent disrupting the diffuse reflectance of the UV beam, which decreases translucency. ${ }^{51}$

The differences in the optical properties originate from different types and amounts of fillers in the PMMA materials. ${ }^{29}$ The difference between the refractive indices of the fillers and matrix affects the refraction and reflection of light at the filler/matrix interface and, thereafter, the translucency of the nanocomposite. ${ }^{52}$ It was found that the refractive index of the nano- $\mathrm{ZrO}_{2}$ (2.1750) is higher than that of the PMMA (1.4813). ${ }^{53}$ Since this nanocomposite was composed of resin and inorganic nanoparticles, the higher the refractive index difference between the two phases, the greater the opacity of the nanocomposite (Figure 5A and B).

From a clinical point of view, an improvement in the mechanical properties of the PMMA denture base via the addition of different fillers and aesthetics is required.

A

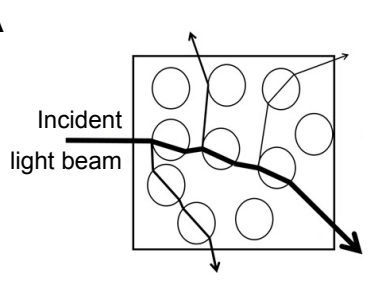

B

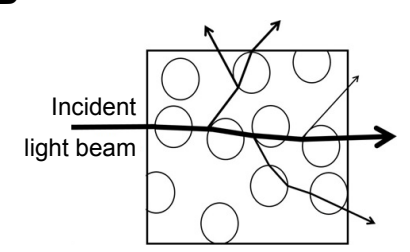

Figure 5 Possible explanation of translucency change of $\mathrm{PMMA} / \mathrm{ZrO}_{2}$ nanocomposite. Notes: (A) Higher refractive index difference between nano- $\mathrm{ZrO}_{2}$ and resin matrix resulted in severe bending of the light at nano- $\mathrm{ZrO}_{2} /$ resin matrix interface, which reduced light transmittance. (B) Low refractive index difference between nano$\mathrm{ZrO}_{2}$ and resin matrix allowed incident light passing through the material with a little interference between nano- $\mathrm{ZrO}_{2}$ and resin matrix.

Abbreviations: PMMA, polymethyl methacrylate; nano- $\mathrm{ZrO}_{2}$, zirconium oxide nanoparticles.
The addition of different concentrations of nano- $\mathrm{ZrO}_{2}$ exhibits an erratic influence on translucency. Therefore, attention should be paid while selecting the appropriate concentrations of reinforcement materials that will improve the mechanical properties with minimal adverse effects on the optical ones.

Nano- $\mathrm{ZrO}_{2}$ particles have received a great attention due to their attractive scientific, technological, and medical aspects. ${ }^{54} \mathrm{Nano}-\mathrm{ZrO}_{2}$ particles were found to possess remarkable antimicrobial and antifungal effects. Several studies reported the positive effects of nano- $\mathrm{ZrO}_{2}$ on Candida albicans and Aspergillus niger. ${ }^{54,55}$ Recently, Gad et al investigated the antifungal effect of nano- $\mathrm{ZrO}_{2}$ incorporated into PMMA removable prosthesis and found that nano- $\mathrm{ZrO}_{2}$ had the capability of reducing the candida counts. This beneficial property allows the incorporation of nano- $\mathrm{ZrO}_{2}$ in the repair material of denture bases and in PMMA removable prostheses as a possible approach to prevent denture stomatitis. ${ }^{56}$ To obtain a PMMA/nanocomposite that holds antimicrobial properties without affecting the physical and mechanical properties, adequate concentrations of nano- $\mathrm{ZrO}_{2}$ should be used. Otherwise, nano- $\mathrm{ZrO}_{2}$ might adversely affect the physical properties of nanocomposites when the focus is directed at treatment outcomes without any attention to material basic properties.

Based on the results of this study, it has been concluded that nano- $\mathrm{ZrO}_{2}$ have a variety of properties due to their specific characteristics and surface activity, thereby making them suitable for polymer reinforcement. When these particles are added to acrylic denture base material, they improve the mechanical properties of the final nanocomposite with an adverse effect on the aesthetic qualities. Further investigations are recommended with different concentrations of nano- $\mathrm{ZrO}_{2}$ and different types of acrylic resins to understand more about the effects of nano- $\mathrm{ZrO}_{2}$ on the physical and mechanical properties of acrylic denture base.

The limitations of this study were using one type of acrylic resin with no aging procedures. In addition to using one reinforcement material, other nanoparticles (titanium, aluminum, silica, etc.) can also be used for reinforcement. Moreover, the specimens were tested in conditions that did not simulate the oral environment. Therefore, the recommendations of this study are to test this nanocomposite after prosthesis fabrication in a simulated oral environment. Further in vivo and clinical studies that investigate the properties of this nanocomposite are also required.

\section{Conclusion}

Within the limitations of this study, the following conclusions could be drawn: addition of nano- $\mathrm{ZrO}_{2}$ to PMMA acrylic 
denture base increases the tensile strength. This increase is directly proportional to the concentrations of nano- $\mathrm{ZrO}_{2}$. The translucency parameter was adversely affected and reduced as the nano- $\mathrm{ZrO}_{2}$ concentration increased. Therefore, caution is necessary when selecting an appropriate concentration that will enhance the mechanical properties of the reinforced PMMA denture base without adversely affecting the aesthetics.

\section{Acknowledgments}

The authors would like to deeply thank Dr Lindsey Mateo and Mr Intisar Siddiqui for their assistance with the mechanical testing and statistical analysis. They would like to extend their thanks to the Institute for Research and Medical Consultations at University of Dammam for granting the opportunity to prepare and study the specimens.

\section{Disclosure}

The authors report no conflicts of interest in this work.

\section{References}

1. Zarb G, Bolender C, Eckert SE. Prosthodontic Treatment for Edentulous Patients: Complete Dentures and Implant-Supported Prostheses. 13th ed. US: Mosby; 2013:135.

2. Katja K, Lippo V, Lassila K. Flexural fatigue of denture base polymer with fiber-reinforced composite reinforcement. Compos Part A Appl Sci Manuf. 2005;36:1177-1324.

3. Franklin P, Wood D, Bubb N. Reinforcement of poly (methyl methacrylate) denture base with glass flake. Dent Mater. 2005;21:365-370.

4. Nagai E, Otani K, Satoh Y, et al. Repair of denture base resin using woven metal and glass fiber: effect of methylene chloride pretreatment. J Prosthet Dent. 2001;85(5):496-500.

5. Asopa V, Suresh S, Khandelwal M, Sharma V, Asopa SS, Kaira LS. A comparative evaluation of properties of zirconia reinforced high impact acrylic resin with that of high impact acrylic resin. Saudi J Dent Res. 2015;2(6):146-151.

6. Nidal WE, Mariyam JG, Andanastuti M, et al. Studies on the effects of titanate and silane coupling agents on the performance of poly (methyl methacrylate)/barium titanate denture base nanocomposites. J Dent. 2017;56:121-132.

7. Mahross HZ, Baroudi K. Effect of silver nanoparticles incorporation on viscoelastic properties of acrylic resin denture base material. Eur $J$ Dent. 2015;9:207-212.

8. Sodagar A, Bahador A, Khalil S, et al. The effect of $\mathrm{TiO}_{2}$ and $\mathrm{SiO}_{2}$ nanoparticles on flexural strength of poly (methyl methacrylate) acrylic resins. J Prosth Res. 2013;57:15-19.

9. Xia Y, Zhang F, Xie H, et al. Nanoparticle-reinforced resin-based dental composites. J Dent. 2008;36:450-455.

10. Gad MM, Fouda SM, Al-Harbi FA, Näpänkangas R, Raustia A. PMMA denture base material enhancement: a review of fiber, filler, and nanofiller addition. Int J Nanomed. 2017;12:3801-3812.

11. Acosta-Torres LS, López-Marín LM, Núñez-Anita RE, et al. Biocompatible of metal-oxide nanoparticles. Nanotechnology improvement of conventional prosthetic acrylic resins. J Nanomater. 2011;2011: 941561-941569.

12. Compagnoni MA, Barbosa DB, de Souza RF, et al. The effect of polymerization cycles on porosity of microwave-processed denture base resin. J Prosthet Dent. 2004;91:281-285.

13. Jordan J, Jacob KL, Shart MA. Experimental trends in polymer nano composites - a review. Mater Sci Eng. 2005;393:1-11.
14. Qain $\mathrm{C}$, Zhang $\mathrm{XY}$, Zhu BS, et al. The effect of $\mathrm{CaSiO}_{3}$ nano-particles reinforced denture polymethyl methacrylate. Adv Compos Lett. 2011; 20:13-20.

15. Chatterjee A. Effect of nanoTiO ${ }_{2}$ addition on poly methyl methacrylate. J Appl Polym Sci. 2010;16:3396-3407.

16. Sun J, Forster A, Johnson P, Eidelman N, Quinn G, Schu-macher G. Improving performance of dental resins by adding titanium dioxide nanoparticles. Dent Mater. 2011;27:972-982.

17. Kango S, Kalia S, Celli A, et al. Surface modification of inorganic nanoparticles for development of organic-inorganic nanocomposites - a review. Prog Polym Sci. 2013;38:1232-1261.

18. Skukla S, Seal S. Phase stabilization in nanocrystalline zirconia. Rev Adv Mater. 2003;5:117-120.

19. Ahmed MA, Ebrahim MI. Effect of zirconium oxide nano-fillers addition on the flexural strength fracture toughness, and hardness of heat-polymerized acrylic resin. World J Nano Sci Eng. 2014;4:50-57.

20. Gad MM, Rahoma A, Al-Thobity AM, et al. Influence of incorporation of $\mathrm{ZrO}_{2}$ nanoparticles on the repair strength of polymethyl methacrylate denture bases. Int J Nanomed. 2016;11:5633-5643.

21. Erjun T, Cheng G, Pang X, et al. Synthesis of nano- $\mathrm{ZnO}_{2} / \mathrm{PMMA}$ composite micros sphere through emulsion polymerization and UV-shielding property. J Colloid Polym Sci. 2005;284(4):422-428.

22. Zappini G, Kammann A, Wachter W. Comparison of fracture tests of denture base materials. J Prosthet Dent. 2003;90:578-585.

23. Ayad NM, Badawi MF, Fatah AA. Effect of reinforcement of high impact acrylic resin with micro-zirconia on some physical and mechanical properties. Rev Clin Pesq Odontol. 2008;4(3):145-151.

24. Gad M, ArRejaie AS, Abdel-Halim MS, et al. The reinforcement effect of nano-zirconia on the transverse strength of repaired acrylic denture base. Int J Dent. 2016;2016:7094056.

25. Singh D, Jayasimha T, Rai KN, et al. Preparation of PMMA nanocomposite with superior impact strength. J Appl Polym Sci. 2007;105(6): 3183-3194.

26. Anusavice KJ. Dental ceramics. In: Phillip's Science of Dental Materials. 11th ed. Missouri: Elsevier Inc.; 2003:721-724.

27. Saridag S, Tak O, Alniacik G. Basic properties and types of zirconia: an overview. World J Stomatol. 2013;2(3):40-47.

28. Hameed HK, Rahman HA. The effect of addition nano particle $\mathrm{ZrO}_{2}$ on some properties of autoclave processed heat cure acrylic denture base material. J Baghdad Coll Dent. 2015;27(1):32-39.

29. Aszrin FN, Takarini V, Hasratiningsih Z, Purwasasmita BS. Translucency evaluation of polymethyl methacrylate (PMMA) reinforced with $\mathrm{ZrO}_{2}-\mathrm{Al}_{2} \mathrm{O}_{3}-\mathrm{SiO}_{2}$ filler system in fabricating indirect restoration. UIP Health Med. 2016;1:1-7.

30. Johnston WM, Ma T, Kienle BH. Translucency parameter of colorants for maxillofacial prostheses. Int J Prosthodont. 1995;8(1):79-86.

31. Yu B, Ahn JS, Lee YK. Measurement of translucency of tooth enamel and dentin. Acta Odontol Scand. 2009;67:57-64.

32. Yu B, Lee YK. Translucency of varied brand and shade of resin composites. Am J Dent. 2008;21(4):229-232.

33. Yu B, Lee Y-K. Influence of color parameters of resin composites on their translucency. Dent Mater. 2008;24(9):1236-1242.

34. Revised American Dental Association specification no. 12 for denture base polymer. J Am Dent Assoc. 1975;90:451-458.

35. Zhang XY, Zhang XJ, Huang ZL, et al. Hybrid effects of zirconia nanoparticles with aluminum borate whiskers on mechanical properties of denture base resin PMMA. Dent Mater J. 2014;33(1):141-146.

36. Yu W, Wang X, Tang Q, Guo M, Zhao J. Reinforcement of denture base PMMA with $\mathrm{ZrO}_{2}$ nanotubes. J Mech Behav Biomed Mater. 2014; 32:192-197.

37. Lung CY, Matinlinna JP. Aspects of silane coupling agents and surface conditioning in dentistry: an overview. Dent Mater. 2012;28:467-477.

38. Liua M, Jiab Z, Jiab D, Zhou C. Recent advance in research on halloysite nanotubes-polymer nanocomposite. Prog Polym Sci. 2014;39: $1498-1525$.

39. Jurišić $\mathrm{S}$, Jurišić G, Zlatarić DK. In vitro evaluation and comparison of the translucency of two different all-ceramic systems. Acta Stomatol Croat. 2015;49(3):195-203. 
40. Hong XY, Wei L, Wei Q. Nano technology: basic concepts and definition. Clin Chem. 2003;40:1400.

41. Haupert F, Wetzel B. Reinforcement of thermosetting polymers by the incorporation of micro- and nanoparticles. In: Friedrich K, Fakirov S, Zhang Z (editors). Polymer composite from nano- to macro-scale. 12th ed. New York, NY: Springer. 2005;5:45-62.

42. Alhareb AO, Akil HM, Ahmad ZB. Impact strength, fracture toughness and hardness improvement of PMMA denture base through addition of nitrile rubber/ceramic fillers. Saudi J Dent Res. 2017;8:26-34.

43. Alhareb AO, Akil HM, Ahmad ZB. Poly (methyl methacrylate) denture base composites enhancement by various combinations of nitrile butadiene rubber/treated ceramic fillers. J Thermoplast Compos Mater. 2015;28(11):1-22.

44. Caravaca C, Shi L, Balvay S, et al. Direct silanization of zirconia for increased biointegration. Acta Biomater. 2016;46:323-335.

45. Otsuka T, and Chujo Y. Poly(methyl methacrylate) (PMMA)-based hybrid materials with reactive zirconium oxide nanocrystals. Polym J. 2010;42:58-65.

46. Chladek G, Kasperski J, Barszczewska-Rybarek I, et al. Sorption, solubility, bond strength and hardness of denture soft lining incorporated with silver nanoparticles. Int J Mol Sci. 2013;14:563-574.

47. Sehajpal SB, Sood VK. Effect of metal filler on some physical properties of acrylic resin. J Prosthet Dent. 1989; 4(61):746-751.

48. Kelly JR, Nishimura I, Campbell SD. Ceramics in dentistry: historical roots and current perspectives. J Prosthet Dent. 1996;75:18-32.
49. Sidhu SK, Ikeda T, Omata Y, Fujita M, Sano H. Change of color and translucency by light curing in resin composites. Oper Dent. 2006;31(5): 598-603.

50. Kim JJ, Moon HJ, Lim BS, Lee YK, Rhee SH, Yang HC. The effect of nanofiller on the opacity of experimental composites. J Biomed Mater Res B Appl Biomater. 2007;80(2):332-338.

51. Shirkavand $\mathrm{S}$, Moslehifard E. Effect of $\mathrm{TiO}_{2}$ nanoparticles on tensile strength of dental acrylic resins. J Dent Res Dent Clin Dent Prospects. 2014;8(4):197-203.

52. Nakajima M, Arimoto A, Prasansuttiporn T, Thanatvarakorn O, Foxton RM, Tagami J. Light transmission characteristics of dentine and resin composites with different thickness. J Dent. 2012;40(2):77-82.

53. Bodurov I, Vlaeva I, Viraneva A, Yovcheva T, Sainov S. Modified design of a laser refractometer. Nanosci Nanotechnol. 2016;16:31-33.

54. Gowri S, Rajiv Gandhi R, Sundrarajan M. Structural, optical, antibacterial and antifungal properties of zirconia nanoparticles by biobased protocol. J Mater Sci Technol. 2014;30:782-790.

55. Jangra SL, Stalin L, Dilbaghi N, et al. Antimicrobial activity of zirconia $\left(\mathrm{ZrO}_{2}\right)$ nanoparticles and zirconium complexes. JNanosci Nanotechnol. 2012;12:7105-7112.

56. Gad MM, Al-Thobity AM, Shahin SY, Alsaqer BT, Ali AA. Inhibitory effect of zirconium oxide nanoparticles on Candida albicans adhesion to repaired polymethyl methacrylate denture bases and interim removable prostheses: a new approach for denture stomatitis prevention. Int J Nanomed. 2017;12:5409-5419.
International Journal of Nanomedicine

\section{Publish your work in this journal}

The International Journal of Nanomedicine is an international, peerreviewed journal focusing on the application of nanotechnology in diagnostics, therapeutics, and drug delivery systems throughout the biomedical field. This journal is indexed on PubMed Central, MedLine, CAS, SciSearch ${ }^{\circledR}$, Current Contents ${ }^{\circledR} /$ Clinical Medicine,

\section{Dovepress}

Journal Citation Reports/Science Edition, EMBase, Scopus and the Elsevier Bibliographic databases. The manuscript management system is completely online and includes a very quick and fair peer-review system, which is all easy to use. Visit http://www.dovepress.com/ testimonials.php to read real quotes from published authors. 